\title{
Using Project Based Learning in a Fundamental Chemistry Course: An Experience Report
}

\author{
Ratana Rungsirisakun, Pisitpong Intarapong, Banyat Lekprasert \\ Ratchaburi Learning Center, King Mongkut's University of Technology Thonburi, Chombueng, Thailand \\ Sukanlaya Tantiwisawaruji \\ Learning Institute, King Mongkut's University of Technology Thonburi, Bangkok, Thailand
}

\begin{abstract}
In this paper, we report the experience received from the project-based learning activity in a fundamental chemistry course. We involved the first year students in Faculty of Engineering at King Mongkut's University of Technology Thonburi, Ratchaburi Learning Center, Thailand. This work considers the innovative activities performed in the field of chemistry and physics. This activity has been intensively implemented in teaching first year students. A project has been created to build up a small machine for measuring the concentration of sucrose solutions. The students participated in a project based learning (PBL) process, in which they worked in groups to create the instrument designed to measure the sucrose concentration in percentage by weight of sucrose in pure water solvent. Project-based learning has gained a greater position in the classroom as researchers have documented what teachers have long understood: Students become more engaged in learning when they have a chance to dig into complex and challenging problems that closely resemble real life. Moreover, several surveys have been conducted along one academic year to evaluate the impact of this method. The results of the surveys show that PBL encourages students' motivation and improves their knowledge involving the project. It is also pointed out that this methodology requires more dedication from lecturers than traditional methodology.
\end{abstract}

Keywords: innovative activities, project based learning (PBL), motivation

\section{Introduction}

Teaching and learning methods have been transformed to project based and activity based learning. The transformation in teaching and learning methods in European universities (Balve \& Albert, 2015) has taken place to increase active learning. The transition from an education system based on lecture base teaching to a project based on learning, making the student the center of the educational process. The application of these new methods of teaching particularly benefits students (Balve \& Albert, 2015; Rodríguez et al., 2015), because they can clearly understand the content by an essential practice component. Active learning methods, such as

Ratana Rungsirisakun, Ph.D., Dr., Ratchaburi Learning Center, King Mongkut's University of Technology Thonburi, Chombueng, Thailand.

Pisitpong Intarapong, Ph.D., Dr., Ratchaburi Learning Center, King Mongkut's University of Technology Thonburi, Chombueng, Thailand.

Banyat Lekprasert, Ph.D., Dr., Ratchaburi Learning Center, King Mongkut’s University of Technology Thonburi, Chombueng, Thailand.

Sukanlaya Tantiwisawaruji, Ph.D., Dr., Learning Institute, King Mongkut's University of Technology Thonburi, Bangkok, Thailand. 
project based learning (PBL) enhances not only the students' acquisition of competences specific of each subject, but also the development of generic competences (Rodríguez et al., 2015; Tasc1 2015) as communication, team work, and leadership as well.

This innovative project has been integrated along the first semester of the engineering degree at King Mongkut's University of Technology Thonburi, Ratchaburi Learning Center. Students have not been exposed to project based learning previously. The main activities implemented are: (a) study of the law of refraction (physics), stoichiometry, and solutions (chemistry); (b) conceptual design of the instrument measured the sucrose concentration in percentage by weight, which have been both integrated in physics and chemistry; and (c) creation of their own instrument (refractometer).

During the first semester of year 2018, the several surveys were conducted. The main objective of these surveys was to evaluate the impact of the PBL methodology in the students' motivation and to determine the students' degree of satisfaction. The principal results are summarized in this work.

\section{Project Description}

The main goal of the project carried out has been giving the students a practicing in using the content in physics and chemistry to solve the science problems. Moreover, students develop their generic skills, such as communication, team work, leadership, and maturity.

The activities of this project are:

(a) Study of the law of refraction (physics), stoichiometry, and solutions (chemistry): Students learns about the law of refraction in the physics class and stoichiometry, and solutions in the chemistry class. Lecturer gives them the problem "How to measure the concentration of sucrose solutions by using the law of refraction".

(b) Conceptual design of the instrument measured the sucrose concentration in percentage by weight, which has been both integrated in physics and chemistry: three to four students per group designing their instrument for measuring the concentration of sucrose solutions. They have to think how to prepare the concentration of sucrose solution: 10, 20,30,40,50,60, and 70\% w/w. Then students present their work plan including conceptual design of the instrument and the method of sucrose solution preparation in various concentrations with the lecturer.

(c) Creation of their own instrument (refractometer): After the work plan is accepted, students will create their own instrument according to their design.

(d) Writing a project summary report.

The learning objectives of this project are: (1) to learn the content of the law of refraction in physics and the concept of stoichiometry and solutions in chemistry by doing this project; (2) to be able to apply the studied theory or content; and (3) to be able to design an instrument (refractometer).

\section{PBL Methodology}

PBL is a learning model that organizes learning around projects. Projects are focused on questions or problems that drive students to encounter the central concepts and principles of a discipline. Moreover, doing project has an impact on skills like self-management, teamwork, leadership, time management, communication, and problem-solving. The benefits of these methodologies are to increase students' motivation and to increase satisfaction of students. Students learn to work together to find solutions to problems. Other advantages of PBL are developing data collection, presentation skills, and thinking skills; students build their own knowledge by 
project based learning, while the teacher only directs and guides.

Students participating in the PBL methodology are arranged in groups of three to four members to organize the conceptual design of the instrument measured the sucrose concentration and to create their own instrument (refractometer). When it involves team work, it is often difficult to identify the effort and results of each student. In this work, the evaluation is done through the following tools:

1. Monitoring of groups in the project classroom: At least two hours per week of team work are conducted with a lecturer who monitors and guides students in their work.

2. Learning diary: Each group of students write a learning diary focused on anything they think, and anything they do in this project work. A lecturer observes the ability in reflection and thinking of students.

3. Regular presentations along the semester: Each presentation is evaluated and, if significant errors are detected, they must be corrected for the final presentation.

4. Oral evaluation at the end of this project: A lecturer gives some questions to all students in the group. Each student has to answer several questions about the principle of their own refractometer, the law of refraction, and the principle of stoichiometry and solutions.

The project is completed in 40 hours of class work (including theoretical classes focused on the project, the oral presentations, and the project classes), during four weeks. The score for each student is obtained from the final report $(30 \%)$, the final oral presentation $(50 \%)$, the learning diary-evaluation $(15 \%)$, and peer evaluation (5\%). The peer evaluation is the appreciation that the lecturers had on the individual work performed by the students. The lecturer should be very careful to peer evaluation.

\section{Results}

This part contains the results of the survey performed to analyze the general perception of students with the project. Table 1 shows the questions of the survey and the mean of each response with the standard deviation. PBL students show a higher interest in the project. In other works, it was reported that most of the students involved in PBL agree that projects help motivate them to increase interest in the subjects involved (Ergül \& Kargın, 2014; Lasauskiene \& Rauduvaite, 2015).

Table 1

Questions in the Survey From 1 (Strongly Disagree) to 5 (Strongly Agree)

\begin{tabular}{lll}
\hline Questions & Average score & Standard deviation (SD) \\
\hline $\begin{array}{l}\text { Doing this project enables students to gain knowledge in preparing solutions } \\
\text { in their daily lives? }\end{array}$ & 4.29 & 0.68 \\
$\begin{array}{l}\text { Doing this project enhances students' motivation to learn chemistry? } \\
\text { Doing this project increases students' skills in using equipment in chemistry } \\
\text { laboratories? }\end{array}$ & 3.85 & 0.84 \\
$\begin{array}{l}\text { Students have more knowledge and understanding of refraction theory. } \\
\text { Students can apply the theory of refraction to create their own instrument } \\
\text { (refractometer). }\end{array}$ & 4.26 & 0.65 \\
Students have the opportunity to practice analyzing the engineering data. & 4.24 & 0.68 \\
Students learn to work together as a team. & 4.51 & 0.71 \\
Students are pleased to learn and work with their friends. & 4.36 & 0.72 \\
$\begin{array}{l}\text { Do you think that with this learning method you learn more? } \\
\text { Do you think with this PBL you develop soft skills that you do not acquire } \\
\text { with the traditional learning? }\end{array}$ & 4.07 & 0.71 \\
\hline
\end{tabular}

Note. This project had 103-student participation. 
The results show that students consider that the PBL Methodology requires more work from them. Students have to adapt their learning styles. Moreover, students sometimes invest too much effort in the project. The students feel that they have to work harder, but they understand that they learn more than with the traditional methodology and develop generic competences which are not educated with the traditional methodology.

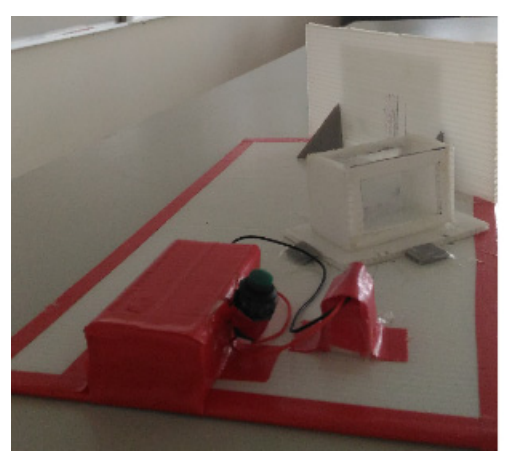

(a)

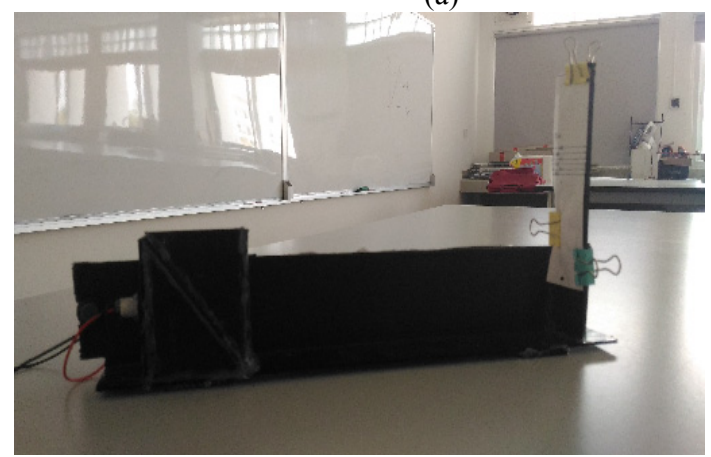

(c)

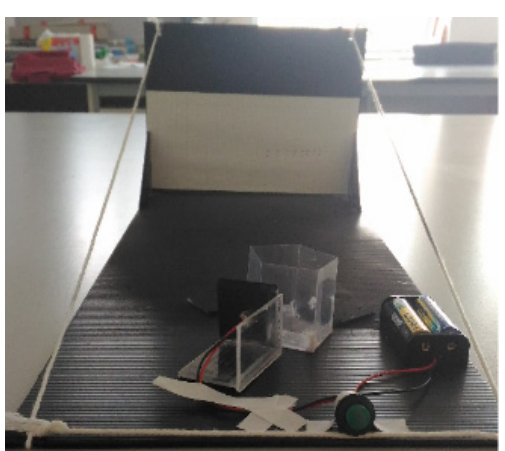

(b)

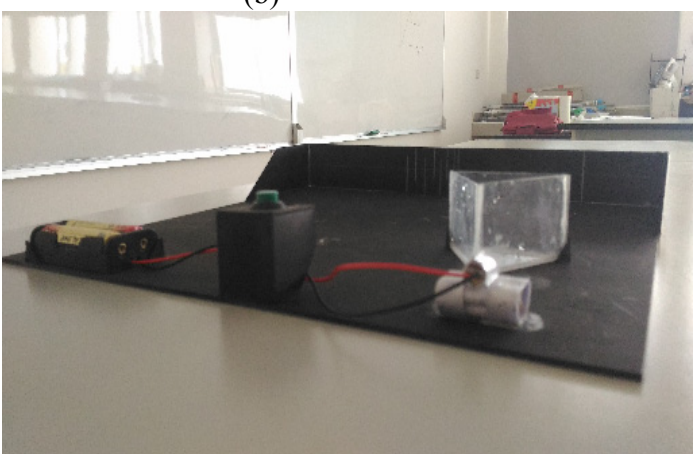

(d)

Figure 1. Examples of instruments (refractometer) created by students.

Table 2

Chemistry Test Score: Calculation of the Amount of Substance in the Solutions

\begin{tabular}{lllllll}
\hline Score & 0 & 1 & 2 & 3 & 4 & 5 \\
\hline Number of students & 6 & 0 & 7 & 9 & 46 & 47 \\
Percentage & 5.22 & 0.00 & 6.09 & 7.82 & 40.00 & 40.87 \\
\hline
\end{tabular}

From Table 2, we found that students have a better understanding of the solutions after doing the project work. There are 93 students (80.87\%, getting 4-5 test score) who can calculate the amount of substance in the solutions according to the defined outcomes. Only six students $(5.22 \%$, getting 0 test score $)$ cannot calculate the quantity of solution after doing the project. Therefore, we conclude that the project work help students understand more about the solutions' calculation because of engaged learning by using the project work. Project-based learning motivates students to deeply obtain knowledge of the studying subjects. There are some researches also indicating that students are more retain the knowledge gained from the active learning far more readily than from traditional teacher-centered learning (Dunlosky, Rawson, Marsh, Nathan, \& Willingham, 2013). In addition, students develop confidence and self-direction as they move through both team-based and independent work. 


\section{Conclusion}

The main objective of this project based learning is to create their own instrument for measuring the concentration of sucrose solution by using the law of refraction. It was found that PBL methodology requires more effort and dedication from students and lecturers than the traditional methodology. The participation in real projects encourages students' motivation. However, students learn more than with the traditional methodology and develop their generic competences. Consequently, students develop deep content knowledge as well as critical thinking, creativity, and communication skills in the framework of doing the project.

\section{References}

Balve, P., \& Albert, M. (2015). Project-based learning in production engineering at the Heilbronn Learning Factory. Procedia CIRP, 32, 104-108.

Dunlosky, J., Rawson, K. A., Marsh, E. J., Nathan, M. J., \& Willingham, D. T. (2013). Effective learning techniques: Promising directions from cognitive and educational psychology. Psychological Science, 14(1), 4-58.

Ergül, N. R., \& Kargın, E. K. (2014). The effect of project based learning on students' science success. Procedia-Social and Behavioral Sciences, 136, 537-541.

Lasauskiene, J., \& Rauduvaite, A. (2015). Project-based learning at university: Teaching experiences of lecturers. Procedia-Social and Behavioral Sciences, 197, 788-792.

Rodríguez, J., Laverón-Simavilla, A., del Cura, J. M., Ezquerro, J. M., Lapuerta, V., \& Cordero-Gracia, M. (2015). Project based learning experiences in the space engineering education at technical university of Madrid. Advances in Space Research, 56(7), 1319-1330.

Tasc1, B. G. (2015). Project based learning from elementary school to college, tool: Architecture. Procedia-Social and Behavioral Sciences, 186, 770-775. 